\title{
Miniaturization of an Electrically Small Metamaterial Inspired Antenna Using Additional Conducting Layer
}

DOI:

10.1049/iet-map.2017.0927

Document Version

Accepted author manuscript

Link to publication record in Manchester Research Explorer

\section{Citation for published version (APA):}

Sharma, S. K., Abdalla, M. A., \& Hu, Z. (2018). Miniaturization of an Electrically Small Metamaterial Inspired Antenna Using Additional Conducting Layer. IET Microwaves, Antennas and Propagation, 12(8), 1444-1449. https://doi.org/10.1049/iet-map.2017.0927

\section{Published in:}

IET Microwaves, Antennas and Propagation

\section{Citing this paper}

Please note that where the full-text provided on Manchester Research Explorer is the Author Accepted Manuscript or Proof version this may differ from the final Published version. If citing, it is advised that you check and use the publisher's definitive version.

\section{General rights}

Copyright and moral rights for the publications made accessible in the Research Explorer are retained by the authors and/or other copyright owners and it is a condition of accessing publications that users recognise and abide by the legal requirements associated with these rights.

\section{Takedown policy}

If you believe that this document breaches copyright please refer to the University of Manchester's Takedown Procedures [http://man.ac.uk/04Y6Bo] or contact uml.scholarlycommunications@manchester.ac.uk providing relevant details, so we can investigate your claim.

\section{OPEN ACCESS}




\title{
Miniaturization of an Electrically Small Metamaterial Inspired Antenna Using Additional Conducting Layer
}

\author{
Sameer K. Sharma ${ }^{1 *}$, Mahmoud A. Abdalla ${ }^{2}$, Zhirun $\mathrm{Hu}^{3}$ \\ ${ }^{1}$ Department of Electrical Engineering, Indian Institute of Technology Kanpur, Kanpur, India \\ ${ }^{2}$ Department of Electronic Engineering, Military Technical College, Cairo, Egypt \\ ${ }^{3}$ School of Electrical and Electronic Engineering, University of Manchester, Manchester, United Kingdom \\ *E-mail: sharma.sameer16@gmail.com
}

\begin{abstract}
An electrically small antenna ensures easy integration with devices without compromising the form factor. Performance in terms of bandwidth, gain etc. for these antennas is extremely critical and is governed by fundamental limitations in size, i.e. Chu's limit. This paper initially presents an analysis on these limits and corresponding performance parameters. Next, a compact dualband antenna has been designed using an electric field driven LC (ELC) resonator and coplanar ground plane which operates at GSM 1800 and Wi-MAX. This proposed antenna has a compact size of $0.31 \lambda_{0} \times 0.08 \lambda_{0} \times 0.01 \lambda_{0}$ in first band which is resonant at $1.89 \mathrm{GHz}$. Finally, a conducting layer is placed below the ELC resonator and both are connected through a via. This provides stronger capacitive coupling between the radiator and the feeding arm and thus, results in miniaturization of $76.9 \%$ in area. The new antenna is electrically small and covers various cellular bands such as GSM 900, Bluetooth, Wi-Fi and Wi-MAX. Prototypes of both designs have been fabricated and experimentally tested in order to validate the simulation results.
\end{abstract}

\section{Introduction}

The wireless industry has seen tremendous growth especially in the last few decades as far as antennas are concerned. It has always been driven by customers with never ending demand for designing compact antennas which can easily be integrated with miniaturized wireless devices. As, their potential is quite large, electrically small antenna (ESA) technologies has been a topic of great interest [1]. These antennas inherently have ground planes in close proximity with the radiating elements which leads to performance issues. Induced surface currents on the ground plane largely cancels the tangential component of alternating current on the radiator surface which results in poor radiation resistance $\left(R_{\text {rad }}\right)$ and narrow bandwidth [2]. Thus, miniaturization in size of such antennas is extremely critical. Performance in terms of gain, bandwidth and radiation efficiency of these ESAs is fundamentally related to their electrical size and quality factor $(Q)$, which has been thoroughly examined by researchers since 1950's [3-5]. Several methodologies for improving the $Q$ and $R_{\text {rad }}$ have also been proposed, such as, by stacking several resonating rings [6], using shorting pins [7, 8], folding [9-11] and introducing slots [12, 13]. A review on these techniques has also been reported in [14]. On the other hand, composite right/left handed (CRLH) transmission lines $[15,16]$ based metamaterial (MTM) antennas have proven to be extremely useful for the design of compact [17], broadband [18], multi-band antennas $[19,20]$, since they allow negative and zeroth-order resonant modes to exist which occur at frequencies much lower than the traditional resonant modes offered by microstrip antennas [21-23]. However, this comes at the expense of low gain, narrow bandwidth and poor radiation efficiency. Such antenna structures have been periodically reported and are available in literature [24-27].

Numerous strategies on miniaturizing the electrical size of antennas is also present in literature [28-32]. In [33], an additional resonant band is generated by exploiting the metamaterial-loading which has a lower frequency as compared to the monopolar resonance. A novel approach for reducing the area of slot antenna has also been presented by virtually enforcing the required boundary condition at the end of the slot antenna by replacing short circuits with inductive or capacitive loadings [34]. A conductor-backed antenna has also been proposed in which the additional layer acts as a ground plane and provides miniaturization in area, but this requires large electrical size [35, 36]. In [37, 38], miniaturization has been realized by altering the geometrical configuration of the split ring resonators. However, these ideas are dependent on antenna designs and operating principles. Non-foster circuits (NFCs) have also been investigated for impedance matching of small antennas at lower frequencies in order to break the fundamental limits. They have proven to be quite effective but seriously fail in stability issues [39]. Also, developing NFCs at S- and C-band are quite challenging which mainly restricts their use in commercial applications.

Through this paper, a simple strategy for reducing the electrical size of compact metamaterial-inspired antenna is presented by loading a conducting layer of copper below the radiating element. This layer is connected to the radiator via pin thereby allowing a stronger capacitive coupling with the coplanar ground plane. This in turn, increases the shunt capacitance of the resulting antenna causing resonating frequency to decrease. The novelty of the work lies in the fact that by employing such a simple strategy and exploiting the information from equivalent circuit models, a size miniaturization of $76.9 \%$ has been realized. Two compact antennas, motivated from CRLH transmission line modeling, have been designed which operate at cellular standards such as GSM $900(0.9 \mathrm{GHz})$, GSM $1800(1.8 \mathrm{GHz})$, Bluetooth $(2.4 \mathrm{GHz})$, Wi-Fi $(2.5 \mathrm{GHz})$ and WiMAX $(3.5 \mathrm{GHz})$. The performance of these antennas have also been compared with designs available in literature. In the next section, performance issues of ESAs have been studied and discussed which are based on fundamental limitations proposed by $\mathrm{Chu}$, McLean and Harrington. In Section III, technique for size reduction has been presented along with the proposed antennas. Equivalent circuit models, parametric analysis of vital geometrical parameters and performance of these antennas has also been discussed. Simulations have been carried out using commercial electromagnetic solver Ansys HFSS 13.0. The results have been validated by fabricating the prototype antennas and testing them experimentally. The major drawback of the finalized structure is a negative gain at first band $(f=0.92 \mathrm{GHz})$ which is largely attributed the small size of the radiating element $\left(0.048 \lambda_{0} \times 0.024 \lambda_{0} \times 0.005 \lambda_{0}\right)$. 
This article has been accepted for publication in a future issue of this journal, but has not been fully edited.

Content may change prior to final publication in an issue of the journal. To cite the paper please use the doi provided on the Digital Library page.

\section{Fundamental limitations on ESA}

In 1947, Wheeler [3] was first to propose that for an antenna to be ESA, its maximum dimension must be less than radian sphere $(\lambda / 2 \pi)$. Chu [4] presented that a lower bound on $Q$ is dependent on physical dimensions of the antenna which restricts its maximum attainable bandwidth $\left(\mathrm{BW}_{\max }\right)$. This is called Chu's limit. McLean [40], modified this work and provided a corrected version for $Q$ and $\mathrm{BW}_{\max }$ which are given below for a fixed value of the voltage standing wave ratio (VSWR).

$$
\begin{gathered}
Q=\frac{1}{k a}+\frac{1}{(k a)^{3}} \\
\mathrm{BW}_{\max }=\frac{\mathrm{VSWR}-1}{Q \sqrt{\mathrm{VSWR}}}
\end{gathered}
$$

where, $k=2 \pi / \lambda$ and $a$ is the radius of the sphere enclosing the antenna. Fig. 1a shows the relationship between minimum $Q$ and size of ESA, dipole and loop antenna. It can be clearly seen that for same quality factor, the size of dipole and loop antenna is higher as compared to ESA. Also, maximum theoretical bandwidth versus electrical size profile is shown in Fig. 1b.

ESAs which are extremely small suffer from narrow bandwidth which also suggests that impedance matching is quite critical in such cases. Also, the alternating current flowing on the antenna surface gets resistance from the induced current on the ground plane as they are quite close. This results in higher energy in the near field which results in poor radiation efficiency and gain respectively. Thus, there exits a bound termed as "Harrington bound" on maximum realizable gain due to electrical size of an ESA [41] which is shown in Fig. 1c and given by equation below

$$
G_{\mathrm{dBi}}=10 \log _{10}\left((k a)^{2}+2 k a\right)
$$

For a ESA $(k a<1)$, the maximum feasible gain is $4.77 \mathrm{dBi}$ and the maximum theoretical bandwidth is $35.3 \%$.

\section{Size Reduction of ESA}

In this section, the design and analysis of two ESAs along with a technique for reducing the electrical size of the same is presented. Initially, an ESA is designed (Antenna 1) to operate at GSM 1800 and Wi-MAX which has a coplanar ground plane. Then, an additional layer of copper is placed below the radiating element such that it shows capacitive coupling with coplanar ground. Also, the radiating element is shorted with this layer via pin. Due to increase in shunt capacitance, resonant frequency decreases which shifts both bands towards a lower frequency bringing in a miniaturization of $76.9 \%$. This finalized structure (Antenna 2) operates at GSM 900, Bluetooth and Wi-Fi.

\subsection{ESA: Antenna 1}

The proposed antenna has been designed of FR4 Epoxy substrate $\left(\epsilon_{r}\right.$ $=4.4, \tan \delta=0.02$ ) with thickness $1.6 \mathrm{~mm}$. It consists of a electric field driven LC (ELC) resonator, main feed and a coplanar ground plane (Fig. 2) along with values of optimized geometrical parameters. Parametric analyses have been carried out on key geometrical parameters in order to obtain an optimized design. Figs. 3a and $3 b$ present the variation of input reflection of proposed antenna with change in gap $(g)$ between feed and ground plane and gap $(s)$ of ELC resonator, respectively. It can be seen that with change in $g$, impedance matching for second band can be improved while there is no shift in frequency bands. However, $s$ plays an important role in deciding the resonance frequency of the first band, as a lower value results in higher capacitance and thus, resonant frequency is lower for $s=0.2 \mathrm{~mm}$ as compared to other values. Due to fabrication tolerance, values below $0.2 \mathrm{~mm}$ were not studied.

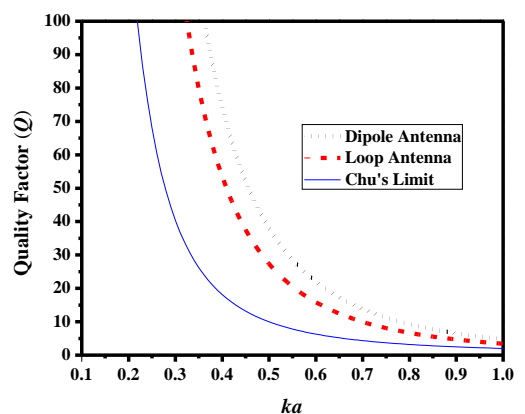

(a)

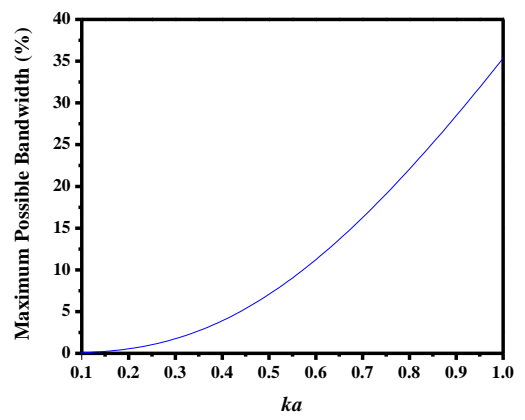

(b)

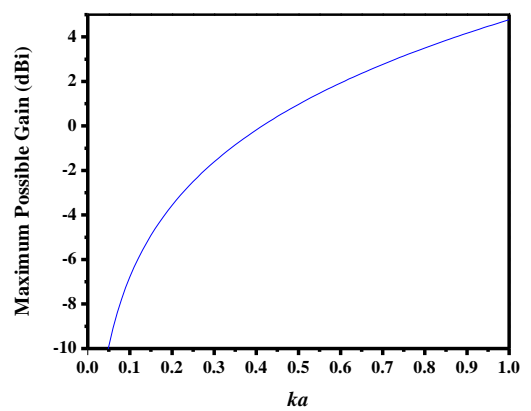

(c)

Fig. 1: Critical performance parameters of electrically small antennas.

$a$ Bound on quality factor $(Q)$

$b$ Bound on impedance bandwidth $\left(\mathrm{BW}_{\max }\right)$

$c$ Bound on gain $(G)$

Fig. 4 shows the equivalent circuit model of proposed antenna based on CRLH transmission line. Here, $L_{1}$ is inductance due to thin conducting line detaching from main feed, $L_{2}$ and $L_{3}$ are inductance due to inner part of ELC resonator and $L_{4}$ is due to closed ring forming the outer part of ELC respectively. Also, $C_{\mathrm{g}}$ is capacitance between main feed and coplanar ground plane, $C_{\mathrm{p}}$ is parasitic capacitance and $C_{\mathrm{OC}}$ is open-circuit capacitance of resonator as it is open-ended.

Measured and simulated input reflection coefficient of the proposed antenna in $1^{\text {st }}$ configuration is shown in Fig. 5 along with fabricated prototype. The S-parameter measurements have been carried out using an Agilent N5320A vector network analyzer (VNA). It can be seen that the proposed antenna exhibits dual-band characteristics, with the first band resonance at $1.89 \mathrm{GHz}$ and the second band centered at $3.2 \mathrm{GHz}$ having impedance bandwidths $\left(\left|S_{11}\right|<\right.$ $-10 \mathrm{~dB}$ ) of $3.7 \%$ and $46.3 \%$, respectively. The designed antenna has a foot print size of $0.31 \lambda_{0} \times 0.08 \lambda_{0} \times 0.01 \lambda_{0}$ at the first resonant frequency of $1.89 \mathrm{GHz}$. Measured results are in good agreement with simulated ones as they show bandwidths of $3.8 \%$ at $1.86 \mathrm{GHz}$ and $41 \%$ at $3.22 \mathrm{GHz}$.

Further, it is quite useful to compare the measured bandwidth of the proposed antenna with the maximum theoretical bandwidth $\left(\mathrm{BW}_{\max }\right)$. Using equations (1) and (2), for $k=38.95 \mathrm{rad} / \mathrm{m}$ at 
This article has been accepted for publication in a future issue of this journal, but has not been fully edited.

Content may change prior to final publication in an issue of the journal. To cite the paper please use the doi provided on the Digital Library page.

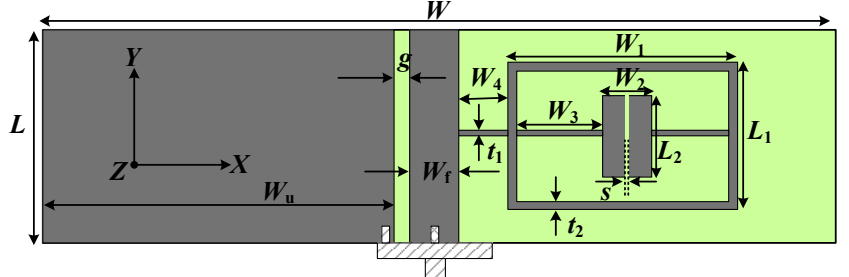

(a)

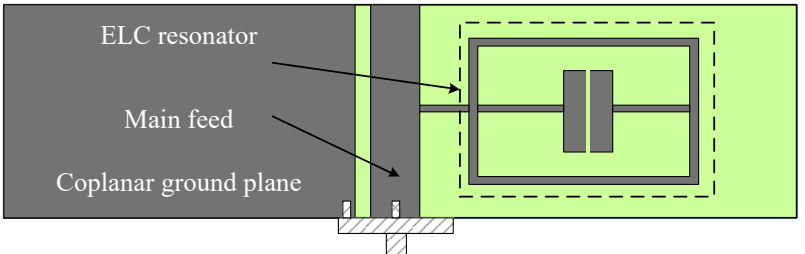

(b)

Copper-Top Layer

FR-4

Fig. 2: Proposed electrically small antenna along with geometrical parameters [All dimensions are in mm: $L=12, W=50, g=0.8, s=$ $0.2, W_{1}=16, W_{2}=2.1, W_{3}=5.4, W_{4}=1.5, W_{\mathrm{f}}=2.4, W_{\mathrm{u}}=23, L_{1}$ $\left.=8, L_{2}=5.6, t_{1}=0.3, t_{2}=0.4\right]$.

$a$ Geometry

$b$ Key elements

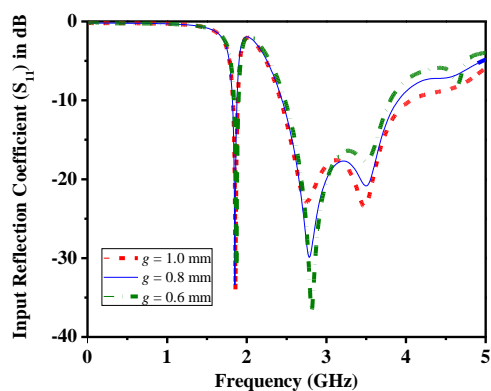

(a)

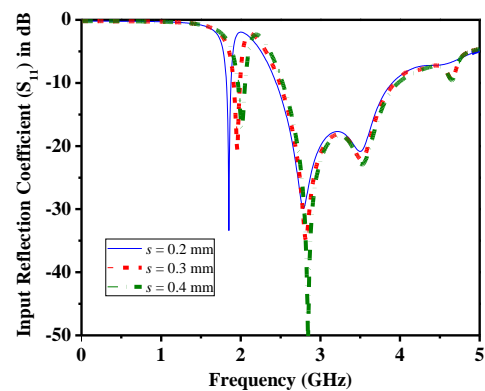

(b)

Fig. 3: Parametric analysis of main geometrical parameters of proposed antenna.

$a$ gap $(g)$

$b$ gap $(s)$

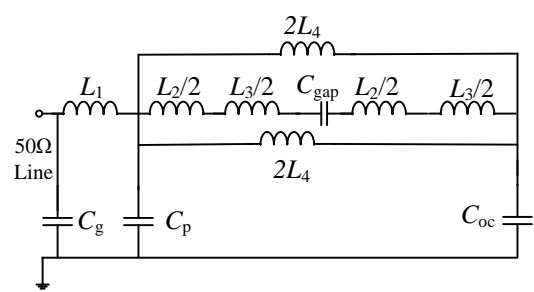

Fig. 4: Equivalent circuit model of antenna 1 based on CRLH transmission line.

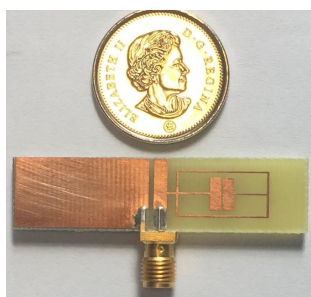

(a)

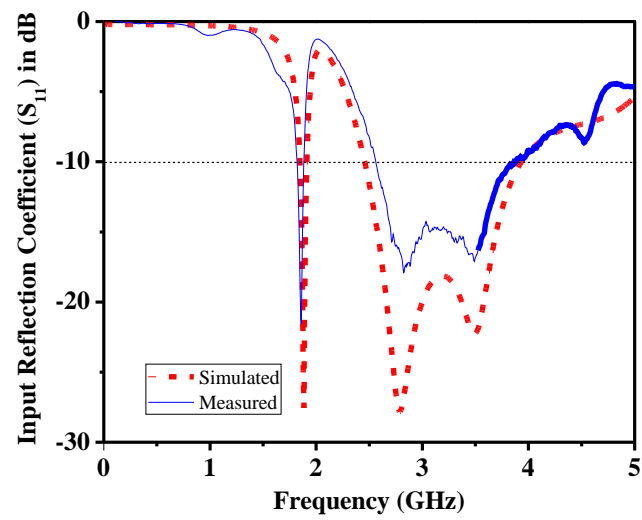

(b)

Fig. 5: Prototype and measurements

$a$ Photo of fabricated prototype

$b$ Comparison of the measured and simulated input reflection coefficients of proposed antenna.

$1.86 \mathrm{GHz}$ and $a=22.82 \mathrm{~mm},(k a=0.89<1)$ and thus, the proposed antenna qualifies as being electrically small. The $Q$ and $\mathrm{BW}_{\max }$ can be evaluated as 2.54 and $27.8 \%$, respectively. However, the measured bandwidth is only around $1 / 7^{t h}$ of the $B W_{\max }$. This indicates that the proposed design is not fully miniaturized and hence, a miniaturization strategy can be employed for size reduction without compromising the performance. Radiation patterns of the proposed ESA are shown in Fig. 6 for $y z$-plane and $x y$-plane at $1.8 \mathrm{GHz}$ and $3.5 \mathrm{GHz}$, respectively. The designed antenna shows an omni-directional pattern in $y z$-plane with low cross-polarization levels. Experiments for radiation patterns have been carried out in ancheoic chamber and measured results are quite consistent with simulated ones. However, losses of $0.27 \mathrm{~dB}$ and $0.42 \mathrm{~dB}$ are observed at $1.8 \mathrm{GHz}$ and $3.5 \mathrm{GHz}$ respectively which can be attributed to the low quality of connectors.

\subsection{Reduced ESA: Antenna 2}

As discussed in the previous subsection, there is a possibility of reducing the size of the proposed antenna even further. Hence, an extra conducting layer consisting of copper with thickness $35 \mu \mathrm{m}$ is placed below the radiating element. The idea is to increase the shunt capacitance by strengthening the capacitive coupling between radiating element and ground plane. Extra care is required to see that the bottom layer should not touch the ground (outer conductor) of the SMA launcher. The radiating element is connected to this layer using a via pin. It also increases the shunt inductance which helps in reduction of frequency and as a consequence, electrical size is reduced. Fig. 7 shows the finalized design (Antenna 2) with an extra layer at the bottom and the corresponding equivalent circuit model can be seen in Fig. 8a. $L_{\text {via }}$ is the inductance due to via pin and $C_{\text {ag }}$ is the capacitor formed between the additional layer and the ground plane which shifts the resonance frequencies of both the bands towards the left.

Comparison between the input reflection coefficients of the proposed antenna in both configurations is shown in Fig. 8b. It can be seen that by loading an extra layer below the radiating element, the resonance frequency for first band is shifted significantly from 
This article has been accepted for publication in a future issue of this journal, but has not been fully edited.

Content may change prior to final publication in an issue of the journal. To cite the paper please use the doi provided on the Digital Library page.

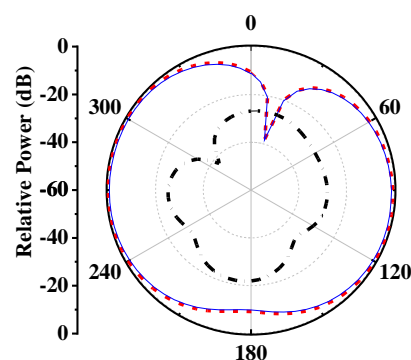

(a)

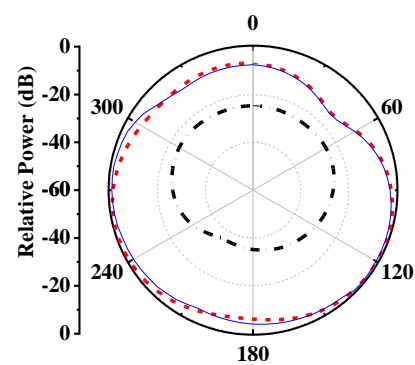

(c)

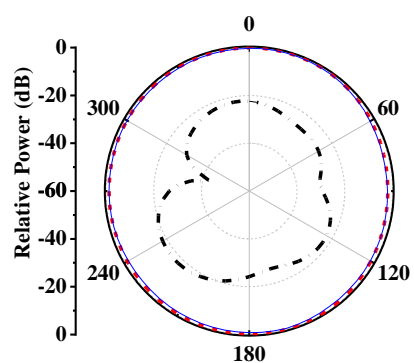

(b)

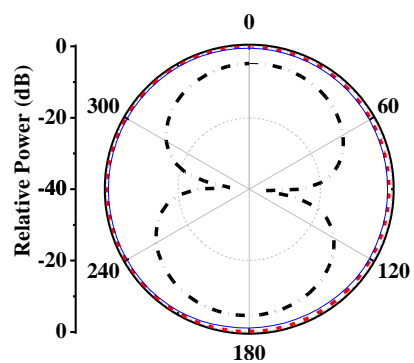

(d)

- Co-pol Simulated - Co-pol Measured - - $\boldsymbol{X}$-pol Simulated

Fig. 6: Radiation patterns of proposed antenna at a $x y$-plane at $1.8 \mathrm{GHz}$

b yz-plane at $1.8 \mathrm{GHz}$

$c x y$-plane at $3.5 \mathrm{GHz}$

$d y z$-plane at $3.5 \mathrm{GHz}$

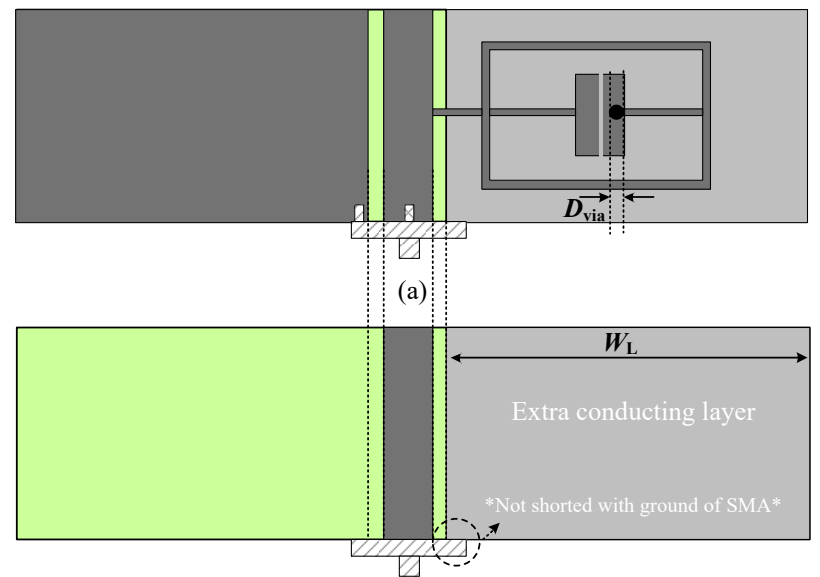

(b)

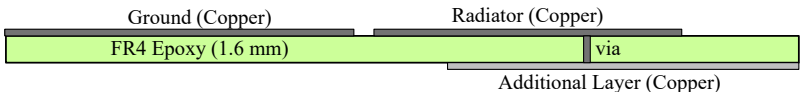

(c)

Copper-Top Layer

Copper-Bottom Layer

FR-4

Fig. 7: proposed electrically small antenna along with geometrical parameters [All dimensions are in $\mathrm{mm}$ : $D_{\text {via }}=0.8, W_{\mathrm{L}}=23.2$ ].

$a$ Geometry

$b$ Key elements

$c$ Side view

$1.89 \mathrm{GHz}$ to $0.92 \mathrm{GHz}$ bringing about a miniaturization in electrical size of about $76.9 \%$, without compromising much on the bandwidth, which is quite remarkable.

Fig. 8c shows the electric field distribution of the proposed antenna (with extra conducting layer) at $0.92 \mathrm{GHz}$ to illustrate the coupling between the lower layer and ground plane. It is clear that

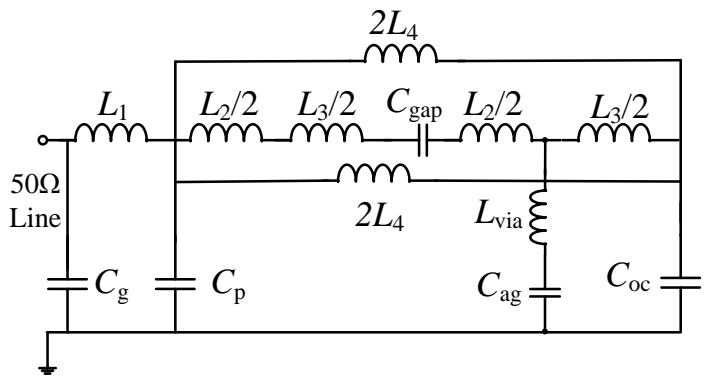

(a)

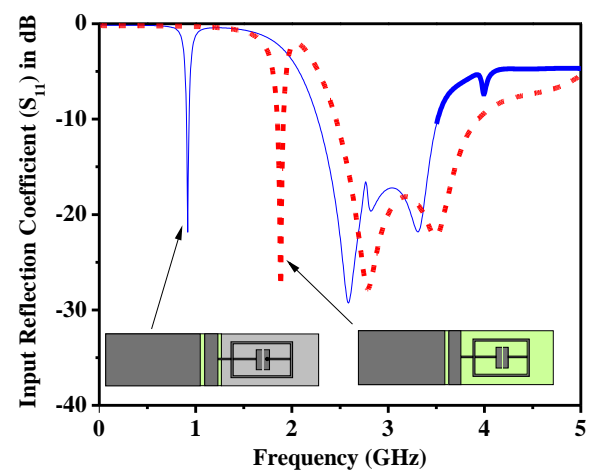

(b)

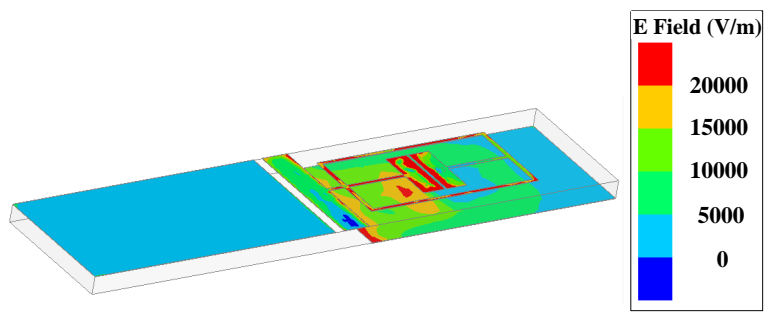

(c)

Fig. 8: Equivalent circuit modeling and simulation results of reduced ESA.

$a$ Equivalent circuit based on CRLH transmission line.

$b$ Comparison between input reflection coefficients of ESA and reduced ESA.

$c$ Electric field distribution

on loading the extra layer, coupling strength increases significantly, which results in a shift of frequency bands, and thus, reduction in electrical size of the proposed design. The effect on the input reflection coefficient of the proposed antennas with variation in width $W_{\mathrm{L}}$ of the additional layer is shown in Fig. 9. It can be seen that $W_{\mathrm{L}}$ has a significant effect on the impedance matching of second band from $2.8-3.5 \mathrm{GHz}$ with slight reduction in bandwidth. Also, it is to be noted that below a certain value of $W_{\mathrm{L}}$, the third resonance completely disappears as $C_{\text {ag }}$ is negligible, which results in degradation of bandwidth.

Fig. 10a shows the top of the fabricated prototype of Antenna $2,10 \mathrm{~b}$ bottom and 10c input reflection coefficient response when it tested experimentally. The proposed structure exhibits impedance bandwidths of $3.5 \%$ (at $0.87 \mathrm{GHz}$ ) and $42 \%$ (at $2.9 \mathrm{GHz}$ ) which are fairly close to the simulated results of $3.3 \%$ (at $0.92 \mathrm{GHz}$ ) and $42.9 \%$ (at $2.89 \mathrm{GHz}$ ). It can be concluded that without compromising much on the bandwidth of the ESA proposed in the previous subsection $(3.7 \%)$, the electrical antenna size can be reduced by $76.9 \%$. In this case, propagation constant $k=18.23 \mathrm{rad} / \mathrm{m}$ at $0.87 \mathrm{GHz}$ and $a=22.82 \mathrm{~mm}, k a=0.416$, which results in a quality factor of 16.3 and maximum theoretical bandwidth $\left(\mathrm{BW}_{\max }\right.$ of $4.3 \%$ which is almost $4 / 3$ of the bandwidth exhibited by antenna 2 . Thus, it can 
This article has been accepted for publication in a future issue of this journal, but has not been fully edited.

Content may change prior to final publication in an issue of the journal. To cite the paper please use the doi provided on the Digital Library page.

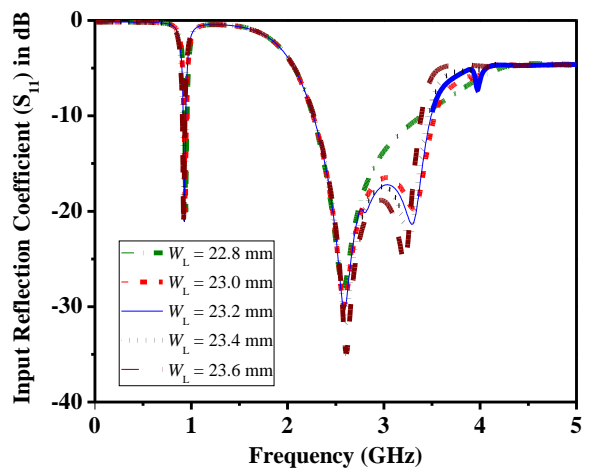

Fig. 9: Input reflection coefficient of proposed antenna in second configuration with change in $W_{\mathrm{L}}$.

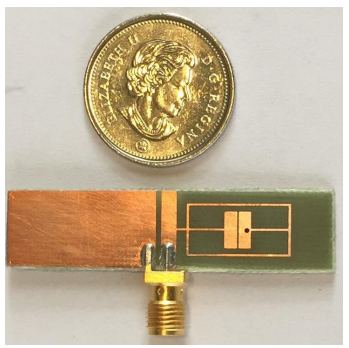

(a)

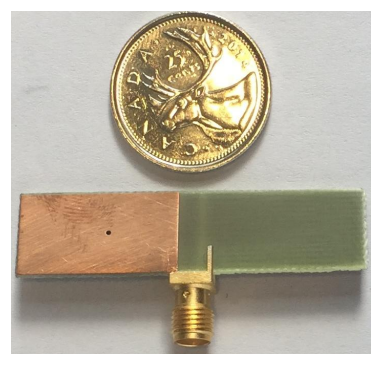

(b)

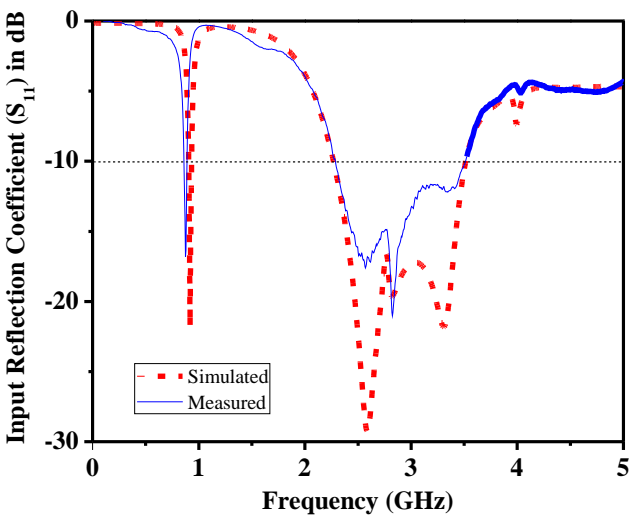

(c)

Fig. 10: Photographs of fabricated prototype and measurement results

$a$ Top

$b$ Bottom

$c$ Measured and simulated input reflection coefficients of proposed antenna with additional layer

be concluded that the performance of an ESA designed in the previous case can be improved by loading an additional layer below the radiating element. Radiation patterns of the proposed antenna in the second configuration are given in Fig. 11 at $0.9 \mathrm{GHz}$ and $2.5 \mathrm{GHz}$ respectively. It can be seen that the measured results are in close proximity when compared to the simulated ones, with measured realized gains, $0.22 \mathrm{~dB}$ and $0.37 \mathrm{~dB}$ lower as compared to the simulated realized gains. Omni-directional characteristics in the $y z$-plane get slightly disturbed due to the presence of the additional conductor layer at the bottom for $0.9 \mathrm{GHz}$ whereas at $2.5 \mathrm{GHz}$, they remain unperturbed.

\subsection{Summary \& Comparison}

Table 1 presents a summary of the performance of the proposed antennas. The finalized antenna is highly miniaturized and offers

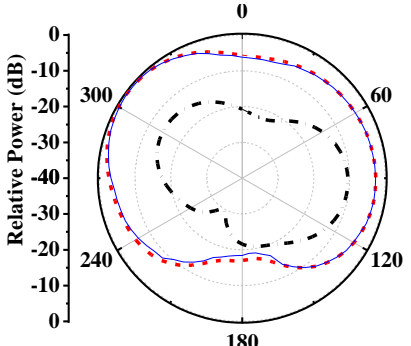

(a)

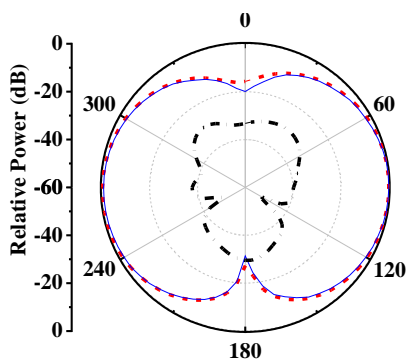

(c)

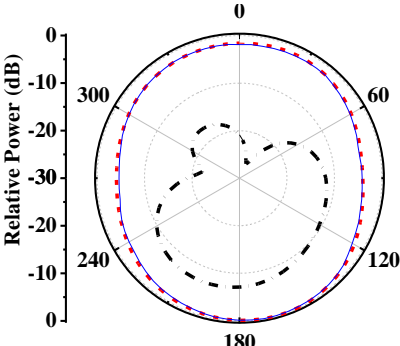

(b)

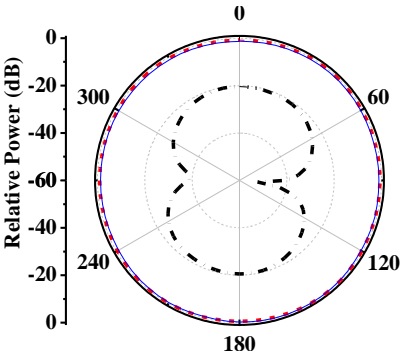

(d)
- Co-pol Simulated $\longrightarrow$ Co-pol Measured - - - X-pol Simulated

Fig. 11: Radiation patterns of proposed antenna at (a) $x y$-plane at $0.9 \mathrm{GHz}$ (b) $y z$-plane at $0.9 \mathrm{GHz}$ (c) $x y$-plane at $2.5 \mathrm{GHz}$ (d) $y z$-plane at $2.5 \mathrm{GHz}$

approximately the same bandwidth as that of the proposed Antenna 1. This miniaturization comes at the cost of realized gain as the final design offers $0.25 \mathrm{~dB}$ lower gain when compared to Antenna 1 which is mainly due to the ultra small radiating element which has an electrical size of $0.048 \lambda_{0} \times 0.024 \lambda_{0} \times 0.005 \lambda_{0}$ at $0.92 \mathrm{GHz}$. The proposed antennas have also been compared with designs which have been previously reported in Table 1 .

It can be seen that the presented designs have better performance in terms of size, bandwidth and gain in most of the cases. However, there are a few inherent drawbacks associated with the miniaturization technique and designs proposed here. As explained earlier, the antennas are highly compact and thus offer low realized gain and also, the strategy of placing a conducting layer below the ground plane results in shifting of both bands due to design issues.

\section{Conclusion}

A simple technique for antenna miniaturization has been presented with two electrically small antennas (ESAs) and their equivalent circuit models. Initially, fundamental limitations on ESAs have been studied and presented followed with the design of a dual-band ESA which operates at GSM 1800 and Wi-MAX. An extra conducting layer is then placed below the radiating element of this ESA which reduces the electrical size by $76.9 \%$ without compromising the bandwidth of the first band. However, the realized gain is compromised to a certain extent. The finalized antenna, thus obtained operates at GSM 900, Bluetooth and Wi-Fi, which makes it an ideal candidate for mobile antennas. Prototype antennas have been fabricated and experimentally validated, showing good agreement with the simulation results.

\section{Acknowledgments}

Authors would like to thank H-D. Lang and T. R. Cameron, University of Toronto for helping in measurements and improving the literature of the paper. 
This article has been accepted for publication in a future issue of this journal, but has not been fully edited.

Content may change prior to final publication in an issue of the journal. To cite the paper please use the doi provided on the Digital Library page.

Table 1 Summary and Comparison of Proposed Antennas with earlier reported antennas

\begin{tabular}{|c|c|c|c|c|c|}
\hline & Freq. (GHz) & Electrical Size(in $\lambda_{0}$ ) & Bandwidth & Realized Gain (dBi) & Rad. Efficiency \\
\hline ESA & $\begin{array}{c}1.89 \\
3.2\end{array}$ & $\begin{array}{l}0.31 \times 0.08 \times 0.01 \\
0.53 \times 0.14 \times 0.02\end{array}$ & $\begin{array}{c}3.7 \% \\
46.3 \%\end{array}$ & $\begin{array}{l}-0.67 \\
2.30\end{array}$ & $\begin{array}{l}44.6 \% \\
98.2 \%\end{array}$ \\
\hline Reduced ESA & $\begin{array}{l}0.92 \\
2.89 \\
\end{array}$ & $\begin{array}{l}0.15 \times 0.04 \times 0.01 \\
0.48 \times 0.12 \times 0.02 \\
\end{array}$ & $\begin{array}{l}3.3 \% \\
42.9 \%\end{array}$ & $\begin{array}{l}-0.92 \\
2.59\end{array}$ & $\begin{array}{l}41.1 \% \\
97.5 \%\end{array}$ \\
\hline [42] & $\begin{array}{l}2.18 \\
7.35 \\
\end{array}$ & $\begin{array}{c}0.14 \times 0.21 \times 0.01 \\
0.49 \times 0.735 \times 0.04\end{array}$ & $\begin{array}{c}4.1 \% \\
69.2 \%\end{array}$ & $\begin{array}{l}0.66 \\
4.44\end{array}$ & $\begin{array}{l}69.8 \% \\
94.1 \%\end{array}$ \\
\hline [43] & $\begin{array}{l}2.50 \\
3.50\end{array}$ & $\begin{array}{l}0.33 \times 0.10 \times 0.01 \\
0.47 \times 0.14 \times 0.02\end{array}$ & $\begin{array}{l}8.2 \% \\
23.7 \%\end{array}$ & $\begin{array}{l}0.03 \\
1.10\end{array}$ & $\begin{array}{l}68.0 \% \\
77.3 \%\end{array}$ \\
\hline [44] & $\begin{array}{l}2.50 \\
2.92\end{array}$ & $\begin{array}{l}0.26 \times 0.22 \times 0.01 \\
0.30 \times 0.25 \times 0.02\end{array}$ & $\begin{array}{l}2.0 \% \\
2.4 \%\end{array}$ & $\begin{array}{l}2.56 \\
3.93\end{array}$ & $\begin{array}{l}69.2 \% \\
98.2 \%\end{array}$ \\
\hline [45] & $\begin{array}{l}2.10 \\
3.10\end{array}$ & $\begin{array}{l}- \\
-\end{array}$ & $\begin{array}{l}0.6 \% \\
0.7 \%\end{array}$ & $\begin{array}{l}-3.60 \\
1.30\end{array}$ & $\begin{array}{l}26.3 \% \\
77.4 \%\end{array}$ \\
\hline
\end{tabular}

\section{References}

Ziolkowski, R. W., and Erentok, A.: 'Metamaterial-based efficient electrically small antennas', IEEE Transactions on Antennas and Propagation, 2006, 54, (7), pp $2113-2130$

2 Sten, J., Hujanen, A., and Koivisto, P. K.: 'Quality factor of an electrically small antenna radiating close to a conducting plane', IEEE Transactions on Antennas and Propagation, 2001, 45, (5), pp. 829-837

3 Wheeler, H. A.: 'Fundamental limitations of small antenna', Proceedings of IRE, 1947, 35, pp. $1479-1484$

4 Chu, L. J.: 'Physical limitations of omnidirectional antennas', Journal of Applied Physics, 1948, 19, pp. $1163-1175$

5 Collin, R. E., and Rothschild, S.: 'Evaluation of antenna Q', IEEE Transactions on Antennas and Propagation, 1964, AP-12, (1), pp. 23-27

6 Peng, L., Chen, P., Wu, A., et al.: 'Efficient radiation by electrically small antennas made of coupled split-ring resonators', Scientific Reports, 2016, 6, (33501)

7 Li, R., Dejean, G., Tentzeris, M. M., Laskar, J.: 'Development and analysis of a folded shorted-patch antenna with reduced size', IEEE Transactions on Antennas and Propagation, 2004, 52, (2), pp. 555-562

8 Chiu, C. Y., Chan, C. H., Luk, K. M.: 'Study of a small wide-band patch antenna with double shorting walls', IEEE Antennas Wireless Propagation Letters, 2004, 3 , pp. $230-231$

9 Porath, R.: 'Theory of miniaturized shorting-post microstrip antennas', IEEE Transactions on Antennas and Propagation, 2000, 48, (1), pp. 41-47

10 Waterhouse, R., Targonski, S., Kokotoff, D.: 'Design and performance of small printed antennas', IEEE Transactions on Antennas and Propagation, 1998, 46, (11), pp. $1629-1633$

11 Wong, K. L.: 'Planar antennas for wireless communications', (John Wiley and Sons, Inc., 2003).

12 Chen, W. -S., Wu, C. -K., Wong, K. -L.: 'Square-ring microstrip antenna with a cross strip for compact circular polarization operation', IEEE Transactions on Antennas and Propagation, 1999, 47, (10), pp. 1566-1568

13 Sharma, S. K., Chaudhary, R. K.: 'Metamaterial inspired dual-band antenna with modified CSRR and EBG loading', 2015 IEEE International Symposium on Antennas and Propagation \& USNC/URSI National Radio Science Meeting, 2015, Vancouver, Canada, pp. 472-473

14 Khan, M. U., Sharawi, M. -S., Mittra, R.: 'Microstrip patch antenna miniaturisation techniques: a review', IET Microwaves, Antennas and Propagation, 2015, 9, (9), pp. 913-922

15 Eleftheriades, G. V., Iyer, A. K., and Kremer, P. C., 'Planar negative refractive index media using periodically LC loaded transmission lines', IEEE Transactions on Microwave Theory and Techniques, 2002, 50, (12), pp. 2702-2712.

16 Best, S. R., 'The significance of composite right/left-handed (CRLH) transmissionline theory and reactive loading in the design of small antennas', IEEE Antennas and Propagation Magazine, 2014, 56, (4), pp. 15-33

17 Sharma, S. K., Gupta, A., Chaudhary, R. K.: 'Compact CPW-fed CHSSR antenna for WLAN ', 2014 IEEE International Microwave and RF Conference, 2014, Bangalore, India, pp. 115-117

$18 \mathrm{Li}, \mathrm{L} ., \mathrm{Li}, \mathrm{Y}$., Yeo, T., et .al: 'A broadband and high-gain metamaterial microstrip antenna', Applied Physics Letters, 2010, 96, 164101

19 Rajkumar, R., Kiran, K. U.: 'A compact metamaterial multiband antenna for WLAN/WiMAX/ITU band applications', AEU - International Journal of Electronics and Communications, 2016, 70, (5), pp. 599-604

20 Abdalla, M. A., Sharma, S. K., Zhirun, H.: 'Asymmetric CRLH cells for compact/wide band triple band antenna for different wireless services', 2017 IEEE International Symposium on Antennas and Propagation \& USNC/URSI National Radio Science Meeting, San Deigo, USA, 2017, pp. 2631-2632

21 Eleftheriades, G. V., and Balmain, K. G.: 'Negative-refraction metamaterials: Fundamental principles and applications', (John Wiley and Sons, Hoboken, New Jersey, 2005)

22 Caloz, C., and Itoh, T., 'Electromagnetic metamaterials: Transmission line approach and microwave applications', (John Wiley \& Sons, Hoboken, New Jersey, 2006)

23 Sharma, S. K., Chaudhary, R. K.: 'A compact zeroth-order resonating wideband antenna with dual-band characteristics', IEEE Antennas and Wireless Propagation Letters, 2015, 14, pp. 1670-1672.

24 Qureshi, F., Antoniades, M. A., and Eleftheriades, G. V.: 'A compact and lowprofile metamaterial ring antenna with vertical polarization', IEEE Antennas and
Wireless Propagation Letters, 2005, 4, pp. 333-336

25 Abdalla, M. A., Wahba, W. W., and Allam, A. M. 'Asymmetric dual-band integrated compact CRLH SIW array antenna', Journal of Electromagnetic Waves and Applications, 2017, 31, (3), pp. 284-296

26 Zhu, J., Antoniades, M. A., and Eleftheriades, G. V.: 'A compact tri-band monopole antenna with single-cell metamaterial loading', IEEE Transactions on Antennas and Propagation, 2010, 58, (4), pp. 1031-1038

27 Sharma, S. K., Mulchandani, J. D., Gupta, D., et .al: 'Triple-band metamaterialinspired antenna using FDTD technique for WLAN/WiMAX applications', International Journal of RF and Microwave Computer-Aided Engineering, 2015, 25, (8), pp. $688-695$

28 Yamamoto, T., Fujimori, K., Sanagi, M., et al.: 'Efficient antenna miniaturization technique by cut off of chromosome-length in genetic algorithm', 2009 Asia Pacific Microwave Conference (APMC), Singapore, 2009, pp. 1837-1840

29 Sharma, C., Vishwakarma, D. K., 'Miniaturization of spiral antenna based on fibonacci sequence using modified koch curve', IEEE Antennas and Wireless Propagation Letters, 2016, 16, pp. 932-935

30 Haque, SK. M., Parvez, K. M.: 'Slot antenna miniaturization using slit, strip, and loop loading techniques', IEEE Transactions on Antennas and Propagation, 2017 65, (5), pp. 2215-2221

31 Ziolkowski, R. W., Jin, P., Lin, C.: 'Metamaterial-inspired engineering of antennas', Proceedings of the IEEE, 2011, 99, (10), pp. 1720-1731

32 Dong, Y., Itoh, T.: 'Metamaterial-based antennas ', Proceedings of the IEEE, 2012, 100, (7), pp. $2271-2285$

33 Zhu, J., Eleftheriades, G. V.: 'Dual-band metamaterial-inspired small monopole antenna for WiFi applications', IET Electronics Letters, 2009, 45, (22), pp. 11041106

34 Azadegan, R., Sarabandi, K., 'A novel approach for miniaturization of slot antennas',IEEE Transactions on Antennas and Propagation, 2003, 51, (3), 421-429

35 Sharma, S. K., Gupta, A., Chaudhary, R. K.: 'Epsilon negative CPW-fed zeroth order resonating antenna with backed ground plane for extended bandwidth and miniaturization', IEEE Transactions on Antennas and Propagation, 2015, 63, (11), pp. 51975203

36 Sharma, S. K., Abdalla, M. A.: 'Size reduction of metamaterial antenna using extra conducting layer for bluetooth, Wi-Fi and WiMAX', 2017 IEEE International Symposium on Antennas and Propagation \& USNC/URSI National Radio Science Meeting, San Diego, USA, 2017, pp. 26292630

37 Alici, K. B., Ozbay, E.: 'Electrically small split ring resonator antennas ', Journal of Applied Physics, 2007, 101, 083104

38 Odabasi, H., Teixeria, F. L., Guney, D. O., 'Electrically small, complementary electric-field-coupled resonator antennas ', Journal of Applied Physics, 2013, 113, 084903

39 Yoon, I. -J., Christebsen, S., Zhurbenko, V., et al.: 'Non-foster impedance matching sensitivity of electrically small electric and magnetic spherical dipole antennas', IET Electronics Letters, 2016, 52, (12), pp. 996998

40 McLean, J. S.: 'A Re-examination of the fundamental limits on the radiation Q of electrically small antennas', IEEE Transactions on Antennas and Propagation, 1996, 44, (5), 672676

41 Harrington, R. F.: 'Effect of antenna size on gain, bandwidth, and efficiency', Journal of Research of the National Bureau of Standards-D. Radio Propagation, 1960, 64D, (1), pp. 112

42 Gupta, A., and Chaudhary, R. K.: 'A compact dual band short ended metamaterial antenna with extended bandwidth', International Journal of RF and Microwave Computer-Aided Engineering, 2016, 26, (5), pp. 435-441.

43 Sharma, S. K., Abdalla, M. A., and Chaudhary, R. K.: 'An electrically small SICRR metamaterial-inspired dual-band antenna for WLAN applications', Microwave and Optical Technology Letters, 2017, 59, (3), pp. 573-578

44 Abdalla, M. A.: 'A high selective filtering small size/dual band antenna using hybrid terminated modified CRLH cell', Microwave and Optical Technology Letters, 2017, 59, (7), pp. 1680-1686

45 Mehdipour, A., Denidni, T. A., and Sebak, A. -R.: 'Multi-band miniaturized antenna loaded by ZOR and CSRR metamaterial structures with monopolar radiation pattern', IEEE Transactions on Antennas and Propagation, 2014, 62, (2), pp. $555-562$ 